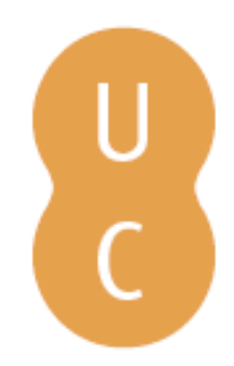

\title{
nommalina
}

\section{Liberdade de indiferença e autoridade individual: a República de Platão sobre a democracia}

\author{
Autor(es): $\quad$ Araújo, Carolina \\ Publicado por: Imprensa da Universidade de Coimbra \\ URL \\ persistente: URI:http://hdl.handle.net/10316.2/45157 \\ DOI: $\quad$ DOI:https://doi.org/10.14195/978-989-26-1679-7_16 \\ Accessed : $\quad$ 26-Apr-2023 16:07:18
}

A navegação consulta e descarregamento dos títulos inseridos nas Bibliotecas Digitais UC Digitalis, UC Pombalina e UC Impactum, pressupõem a aceitação plena e sem reservas dos Termos e Condições de Uso destas Bibliotecas Digitais, disponíveis em https://digitalis.uc.pt/pt-pt/termos.

Conforme exposto nos referidos Termos e Condições de Uso, o descarregamento de títulos de acesso restrito requer uma licença válida de autorização devendo o utilizador aceder ao(s) documento(s) a partir de um endereço de IP da instituição detentora da supramencionada licença.

Ao utilizador é apenas permitido o descarregamento para uso pessoal, pelo que o emprego do(s) título(s) descarregado(s) para outro fim, designadamente comercial, carece de autorização do respetivo autor ou editor da obra.

Na medida em que todas as obras da UC Digitalis se encontram protegidas pelo Código do Direito de Autor e Direitos Conexos e demais legislação aplicável, toda a cópia, parcial ou total, deste documento, nos casos em que é legalmente admitida, deverá conter ou fazer-se acompanhar por este aviso.

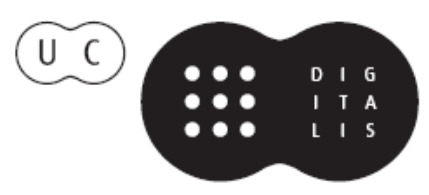



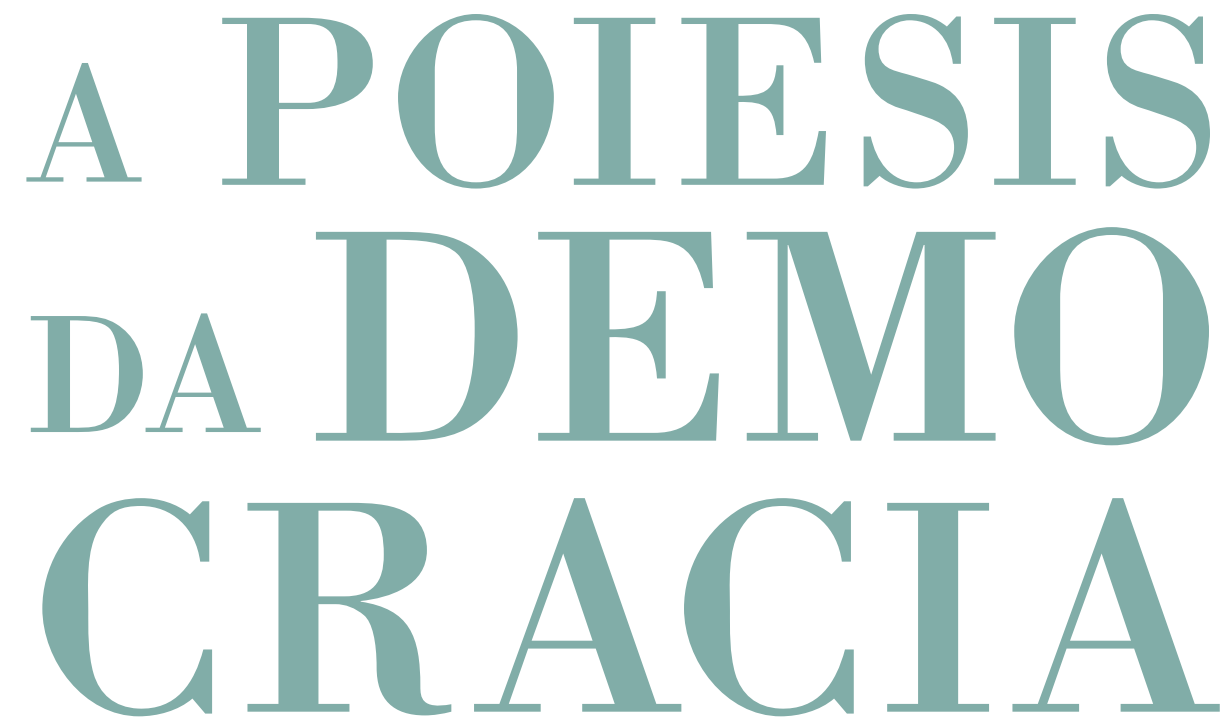

G

Breno Battistin Sebastiani, Delfim Leão,

Lugia Sano, Martinho Soares, Christian Werner

\section{CoimbraCompanions}




\title{
Liberdade de indiferença $e$ \\ autoridade individual:
}

\author{
A RePÚblica de Platẽo SOBRE A \\ DEMOCRACIA
}

FREEDOM OF INDIFFERENCE AND

INDIVIDUAL AUTHORITY:

PLATO'S REPUBLIC ON DEMOCRACY

Carolina Araújo

Universidade Federal do Rio de Janeiro

ORCID | 0000-0001-6144-8077 


\section{Resumo}

A análise da democracia que se encontra na República de Platão foi frequentemente objeto de derrisão. Neste trabalho pretendo mostrar que, ainda que concedendo que Platão tenha uma visão peculiar da questão, sua posição não corresponde à caricatura que lhe atribuem os críticos. Trata-se de argumentar que aos olhos de Platão os caracteres humanos são democráticos quando tomam a liberdade de indiferença como bem prevalente. Por outro lado, ela se aplica a regimes políticos quando a sua regra fundamental é a autoridade individual, sustentada pela prática da tolerância. Concluo ressaltando que, embora democracia seja um termo equívoco ao referir-se a antigos e modernos, as questões levantadas pela República ainda vigoram nas discussões sobre a liberdade e o pluralismo político.

\section{Palavras-chave}

Democracia, Platão, República, liberdade, tolerância 


\section{Abstract}

The analysis of democracy we find in Plato's Republic was often an object of derision. In this paper I intend to show that, granting that Plato has a peculiar perspective of the matter, his position does not correspond to the caricature imputed by the critics. My purpose is to argue that in Plato's view human characters are democratic when they take freedom of indifference as the prevailing good. On the other hand, it applies to political regimes when their fundamental rule is the individual authority, sustained by the practice of tolerance. I conclude by pointing out that, although democracy is an equivocal term when dealing with ancients and moderns, the questions raised by the Republic are still alive in the discussions about freedom and political pluralism.

\section{Keywords}

Democracy, Plato, Republic, freedom, tolerance 
A descrição da democracia feita por Platão na República (555b4-564c6) ${ }^{1}$ foi frequentemente ridicularizada, quer por se tratar de uma peça de propaganda política², quer por representar uma crítica à própria noção de política e esfera pública ${ }^{3}$, quer por apresentar sérios problemas de coerência. ${ }^{4}$ Neste trabalho pretendo mostrar que, ainda que seja um equívoco supor qualquer historicidade nesse tratamento da democracia, as questões ali tratadas propõem problemas ainda relevantes às nossas experiências democráticas no que tange aos conceitos de liberdade, individualismo, comunidade, pluralismo e tolerância.

A primeira seção do trabalho é metodológica e pretende desarmar algumas das usuais objeções ao argumento. Começo por defender, de modo breve, uma interpretação propriamente analógica da relação entre alma e cidade no que toca à descrição da democracia. Também apresentarei razões para evitar tanto uma leitura "personalista" quanto uma leitura historicista da passagem. Proponho que se trata aí de uma investigação normativa das regras de vida, sejam elas individuais ou coletivas, i.e., uma análise de determinados princípios valorativos com o objetivo de auferir a sua coerência

1 Todas as referências unicamente numéricas são à edição da República de Platão de Slings 2002 .

2 "A descrição platônica da democracia é uma paródia vívida porém altamente hostil e injusta da vida política de Atenas (...); é uma brilhante peça de propaganda política." (Popper 1971: 42).

3 "Essa tentativa de substituir a ação pela produção é manifesta em todo o corpo do argumento contra a 'democracia', o qual, quando mais consistentemente e melhor justificado, tornar-se-á um argumento contra a essência da política”. (Arendt 1958: 220).

4 "Platão parece disposto a confundir duas coisas muito diferentes: uma cidade na qual há vários caracteres entre as pessoas e uma cidade na qual a maioria das pessoas tem um caráter variado, ou seja, um caráter mutável e instável" (Williams 2008: 260); "Platão está confundindo uma cidade formada por uma variedade de tipos de pessoas com uma cidade formada por pessoas que são, cada uma delas, uma variedade individual. Ele almeja o primeiro, dar um relato coerente sobre a cidade democrática, mas a insistência em que a cidade e a alma são paralelas leva-o ao segundo" (Annas 2009: 301). 
na produção, de um lado, da felicidade pessoal e, do outro, do bem comum. A segunda parte aborda a tese sobre a formação do caráter apresentada na República e a sua repercussão no tratamento do caráter democrático. A posição defendida é de que o texto argumenta que a alma é livre por espontaneidade: ela é princípio de sua ação, agente de deliberação e responsável última pelo caráter que adquire. Na descrição da alma democrática, por sua vez, um outro conceito de liberdade vai ser atribuído ao agente, o da liberdade de indiferença. Dela apresento a definição, seus efeitos na deliberação e ações consideradas democráticas. Na terceira seção desse trabalho concentro-me na discussão da democracia como regime político e pretendo mostrar que a noção de autoridade individual (exousia) explica a visão platônica da democracia como um sistema de governo pluralista no qual nenhuma regra coletiva é tida como legítima. A crítica platônica à democracia diz portanto respeito a problemas advindos, por um lado, da liberdade de indiferença e, por outro, do pluralismo político.

\section{A analogia entre cidade e alma}

A analogia entre cidade e alma constitui o método que estrutura todo o argumento da República de Platão. ${ }^{5}$ Ela surge da hipótese de que o significado de justiça seja o mesmo quando o termo é predicado de indivíduos ou de cidades. Essa hipótese é confirmada por uma análise do que são a cidade - em sua legislação - e a alma - em sua deliberação. Ao contrário do que pensam alguns estudiosos ${ }^{6}$, Sócrates jamais infere uma da outra (cf. 434d-435a), e isso resulta em um argumento que define não apenas a justiça, mas as demais virtudes, e além delas os quatro vícios, sempre de modo duplo: primeiramente na cidade e a seguir na alma. ${ }^{7}$ Em todas essas definições, as versões cívica e individual são tidas como referindo-se a um

5 A analogia é propriamente, como mostra Blössner (1997: 55), uma técnica literária e não um dogma platônico.

6 Cf. por exemplo Santas 2001: 60; Helmer 2005: 159.

7 Cf. Demos 1957: 171; Ferrari 2005: 60; Blössner 2007: 382. 
sentido unívoco: trata-se em todas elas de variantes do governo (kratos, arche), ditas como aristocracia, timocracia, oligarquia, democracia e tirania.

Por governo entende-se aqui a estabilidade da prerrogativa de um determinado tipo de valor ou motivação - na verdade veremos que se trata de um objeto que aparece como bom, ou ainda, um bem aparente - sobre os demais. ${ }^{8}$ Essa prevalência se exprime em uma regra de organização interna. É porque uma tal organização não pode ser atribuída a unidades, nem a partes de um conjunto enquanto tais, mas apenas a um todo composto de partes segundo a sua organização interna, que tais regras nunca são atribuídas aos cidadãos de uma cidade` ou a certas ações de um indivíduo. Por conseguinte, não faz sentido a crítica de Williams ${ }^{10}$ de que Platão entendeu a democracia como uma composição de cidadãos democráticos porque Platão, ao falar de democracia, supõe que ela seja uma certa regra de organização de um todo que se refere à função política de seus cidadãos e não a traços de sua personalidade.

Dessa interpretação estritamente analógica decorre uma outra consequência metodológica. Muitos são os comentários ao livro VIII que se queixam de como as chamadas instituições políticas são menosprezadas. ${ }^{11} \mathrm{O}$ regime espartano, por exemplo, consistia em leis sobre educação pública, algumas delas bem próximas às propostas por Sócrates na República, e isso parece ter pouco em comum com uma timocracia definida por governantes que apenas aparentemente zelam pela honra, mas essencialmente buscam o acúmulo de riquezas. A razão dessa dissonância é que a passagem se dedica, como disse, à avaliação normativa de princípios valorativos que se exprimem no nomos de um regime ou na concepção de felicidade de um caráter. O fato de que o nomos não se restringe à letra da lei e a formas políticas

\footnotetext{
8 Infelizmente não há espaço aqui para que essa interpretação seja devidamente argumentada, limito-me a remeter para o que parece ser a evidência textual que a suporta, a tese de que, embora haja indeterminadas formas de mau governo, o problema pode ser tratado pela investigação de quatro padrões básicos (445c6-7 e 544a2-8). Sobre a regra do método diairético que identifica esses padrões, cf. Hellwig 1980: 21 ss.

9 Como nos mostra 428e-429a, há vários indivíduos que não são politicamente sábios em uma cidade justa.

10 Cf. nota 4.

11 Cf., por exemplo, Barker 1959: 182 e Annas 2009.
} 
institucionais, mas abrange todo o costume vigente de um determinado grupo, ou ainda, que nossas suposições sobre a felicidade se revelam antes em nossas escolhas do que em nossos discursos, faz com que interesse menos aos interlocutores do diálogo quais são as regras escritas ou proferidas de um regime, mas muito mais quais são as ações que aí se encontram. Seguindo uma tendência antiga grega, a teleologia, o livro VIII descreve práticas, movimentos e ações por seus propósitos, entendidos como uma concepção de finalidade ou bem. A investigação normativa que encontramos na República é portanto uma análise de uma noção de "bem prevalente" que unifica uma comunidade ou um caráter, e da medida em que esse bem promove algo que possa ser coerentemente descrito como harmonia psíquica ou bem comum. Como veremos, portanto, a classificação não é de "regimes históricos", mas de tipos de bens aparentes. ${ }^{12}$

Entender o método dessa investigação segundo esses parâmetros também nos dá motivos para resistir a um recurso muito presente nas análises sobre a crítica platônica à democracia em particular. Muitos são os comentários ${ }^{13}$ que recaem em argumentos personalistas ou biográficos que contemporizam as duras palavras do texto alegando uma "decepção" platônica com o regime ateniense de sua época, responsável pela morte de seu protagonista preferido. Entendo que essa abordagem é duvidosa e problemática. Não se trata de negar a evidência da dramaticidade - por vezes até do sentimentalismo de certas passagens do corpus platônico que retratam a democracia ateniense em confronto com o filósofo. Porém, a tese da decepção tem por pilar não apenas indícios textuais produzidos pelo autor, mas suas intenções e valores, o que requer, em última análise, o apoio de biografias de Platão de fontes altamente precárias, tal como a controversa Sétima Carta.

Há ainda um terceiro sentido pelo qual minha abordagem se contrapõe a perspectivas influentes de leitura da passagem. O texto platônico do livro VIII se propõe a apresentar dois critérios de investigação: a gênese e as propriedades de cada regime anímico ou político (cf. por exemplo $\tau i ́ v \alpha \tau \varepsilon$

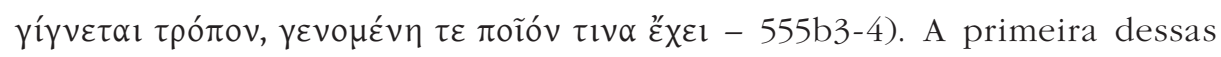

12 Para conclusão semelhante por outros argumentos, cf. Romilly 1959: 99.

13 Cf. por exemplo, Bertelli 2005: 295 
etapas, que eu chamarei aqui - por falta de expressão melhor - de explicação genética, foi amplamente confundida, principalmente depois de Popper $^{14}$, com uma tese historicista. Frede ${ }^{15}$ já ofereceu bons argumentos contra essa abordagem, sobretudo indicando que não há elos de necessidade explicando a sucessão degenerativa. ${ }^{16}$ Como se trata de regimes que são por definição corrompidos e instáveis, esse bem é transitório e explica tanto a geração quanto a corrupção do regime. Porém Frede, e outros, não se detêm em explicar a diferenciação entre os dois momentos do argumento - o da gênese e o das propriedades. Proponho aqui que a investigação sobre a "origem" de um regime político ou caráter da alma nada mais é que uma certa narrativa que busca identificá-lo segundo um critério primeiro, qual seja, o dito bem prevalente. Entendo que no argumento de República VIII esse bem é considerado a instituição política mais fundamental e a concepção de felicidade segundo a qual os indivíduos agem e formam o seu caráter. A segunda parte do argumento, que apresenta as propriedades dos regimes e caracteres, explica como o bem prevalente atua, seja nas escolhas de um indivíduo, seja na produção do bem comum. No caso dos regimes políticos, ele estabelece quem exercerá o governo, e, no caso dos caracteres, que ações serão tomadas. É essa análise das propriedades que vai possibilitar o caráter propriamente normativo da investigação, uma vez que nos proporciona elementos para julgar o sucesso do regime e a felicidade do caráter. Vejamos então como isso se apresenta, a começar pelo caráter da alma.

\section{A alma e a alma democrática}

\subsection{Liberdade como espontaneidade}

Do que foi dito na seção anterior, comprometemo-nos com a tese de que indivíduos podem se organizar internamente pela prevalência de um

14 Cf. Popper 1971: 18 ss.

15 Cf. Frede 2011: 195-197.

16 Frede 2011: 206. 
determinado bem. Para isso, é preciso que se mostre que tipo de componentes seriam assim organizados ${ }^{17}$ e a República nos oferece um argumento pelo qual motivações ou estados intencionais poderiam ser entendidos como diferentes itens internos que são organizados segundo nossas escolhas. Esse argumento depende da suposição de que as ações de um indivíduo são sempre resultantes da organização dessas motivações, ou seja, decorrem imediatamente da prevalência de uma concepção de bem sobre as demais. Essa suposição depende da aceitação de um princípio que diz: o mesmo não quererá fazer ou sofrer opostos ao mesmo tempo segundo o mesmo e em relação ao mesmo, de modo que se encontrarmos isso a ocorrer em algo,

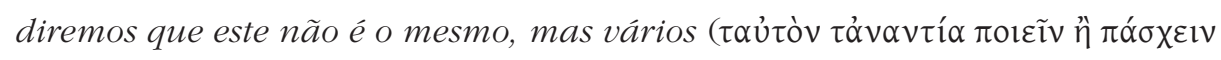

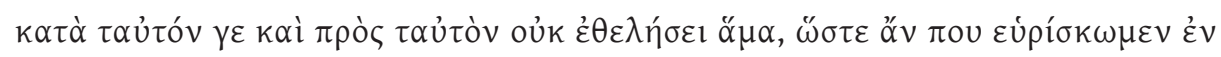

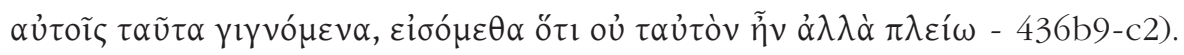

Antes de mais, essa não é uma versão do princípio de não-contradição. ${ }^{18}$ Seu sujeito "o mesmo" não é uma proposição, mas um agente (ou, na versão alternativa, um paciente). Tal agente não quererá fazer opostos sob as condições assim estabelecidas, a sua deliberação é sempre por uma única ação. O primeiro exemplo dessas ações opostas, bem mais simples, é o do estar em repouso ou se movimentar (436c6-7). Essa oposição pode perfeitamente ser de partes do agente, mas não do agente como um todo, como mostram os contraexemplos que Sócrates apresenta para serem rejeitados: (i) um homem que está parado e move os braços e a cabeça, está parado segundo as pernas e em movimento segundo os braços e a cabeça (436c10-d2); (ii) o pião que gira se move segundo o seu eixo, mas está parado segundo o espaço ao seu redor (436d5-e5)19; (iii) um arqueiro que verga um arco o puxa segundo uma mão e o empurra segundo a outra (439b8-c1). Em todos os casos a simultaneidade de ações contrárias não pode ser atribuída a um agente sem mais, é preciso inserir um qualificativo.

17 Tais componentes são por vezes chamados de eidos (435c1, c5, e1, 437b8), por vezes genos (435b7, 441c6, 441d8), por vezes meros e tradicionalmente ficaram conhecidos por "partes da alma".

18 Como supõe Adam (1902: 246); cf. os argumentos contra essa hipótese em Robinson (1971: 38).

19 Cf. Stalley 1975: 112 ss. 
Por outro lado, os exemplos mostram - e esse é bem o propósito do argumento - que a ação do agente não é incompatível com a presença de contrariedade entre suas "partes" assim qualificadas, desde que esses não se confundam com a ação do agente enquanto tal, que é determinada pela resultante de todas essas ações de suas partes.

O qualificativo "segundo" aparece nos exemplos em referência a partes facilmente identificáveis nos agentes. Quando porém o problema é a alma, aquilo segundo o que há contrariedade depende da construção da individuação dessa ação. Movimento e repouso de corpos e suas partes são perceptíveis: eu vejo que a mão está em movimento e a perna em repouso, distinguindo essas duas partes. Já os movimentos da alma, não. Por isso é importante a

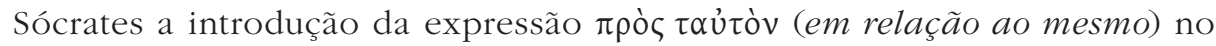
enunciado do princípio. Ao introduzir as ações contrárias relevantes ao argumento - afirmar ou negar (437b1), desejar ou recusar (437b1-2), ser atraído ou repelir (437b2-3) -, Sócrates precisa de as apresentar como relativas a determinados objetos, afinal esses verbos não são semanticamente completos como no caso de mover-se e estar em repouso. Eles portanto implicam que há algo - coisas, propriedades, estado de coisas - a ser representado pelo agente como algo que se quer obter ou repelir, i.e., como algo que aparece como um bem ou como um mal, e que pode individuar cada uma das ações opostas. Isso inclusive coaduna com a tese sustentada por Sócrates pelo menos duas vezes no texto da República, 413a4-5 e 505d59, de que nossas ações são sempre em vista do bem, afinal toda prevalência de uma motivação é prevalência de um objeto que aparece como bem. Ademais, é certo que assim Platão se compromete com a tese de que não há uma terceira opção de ação em que o objeto é irrelevante ou indiferente.

Voltemos então ao princípio: fica agora claro o uso do verbo ethelo: querer, ter intenção, ou ainda, desejar ou conceder a um desejo. O que o princípio diz é que o agente, enquanto tal, não pode deliberar por ações contrárias simultaneamente, embora possa eventualmente deliberar por uma ação que pretenda conjugar diversas motivações. Por conseguinte, o que Sócrates entende como ações contrárias das partes não pode ser rigorosamente 
uma ação de um subagente ${ }^{20}$, aliás é isso o que o princípio nega fortemente ao afirmar a unidade do agente. Toda ação, dadas as condições estabelecidas no princípio, será sempre uma ação única, excluídas todas as alternativas, por isso toda ação é uma ação de governo. ${ }^{21} \mathrm{O}$ que gostaria de defender portanto é que o princípio se aplica a circunstâncias de deliberação nas quais as alternativas são reduzidas a duas - assimilar $\mathrm{X}$ e repelir $\mathrm{X}$-, onde $\mathrm{X}$ é o objeto de um estado intencional que já o representa como um bem a ser buscado ou um mal a ser evitado, e onde o agente necessariamente decidirá por apenas uma ação em relação a X.

Se isso está correto, trata-se aqui de um princípio prático sobre a liberdade da deliberação, estipulado por apelo à nossa experiência interna do conflito motivacional e que estabelece algo correspondente ao que chamamos hoje causação por agente. Portanto, o que nos é apresentado é a tese da liberdade entendida como espontaneidade, classicamente descrita na formulação cartesiana de que "podemos fazer uma coisa ou deixar de fazer (isto é, afirmar ou negar, perseguir ou fugir)". ${ }^{22}$

A alma, e não as suas partes, é portanto responsável por sua ação. Essa imputabilidade aparece tanto no horror de Leôncio a bradar contra o governo da sua alma pelo desejo - afinal é Leôncio e não seu desejo quem olha os cadáveres (440a2-4) -, quanto no elogio ao heró́smo de Odisseu ao conter a sua ira (441b3-c2). O fato de que Platão se compromete com a tese de que um bem verdadeiro determina nossas escolhas quando somos capazes de reconhecê-lo como tal não nega a espontaneidade do agente. Em primeiro lugar, porque não estamos tratando aqui de um conceito de liberdade da

20 Para a defesa de que a República se compromete com partes da alma como "homúnculos" e a enumeração dos problemas que decorrem dessa suposição, cf. Bobonich 2002: 219-257.

21 Uma única motivação governa a alma como um todo, sem fazer com que as demais cessem de existir; afinal aqueles que têm sede e não bebem ainda são, por definição, sedentos (439c3-4).

22 Descartes, Meditações Metafísicas, IV, § 9. A dificuldade da aproximação entre Platão e Descartes está em que, em Platão, a capacidade racional não é, como quiseram os medievais, simplesmente uma cognição causal e o estabelecimento de meios e fins, tese que levou esses medievais a supor a vontade como faculdade distinta da razão exatamente devido à sua liberdade. Não obstante, Platão introduz uma teoria da liberdade da alma a partir da suposição de que a razão tem uma força prática, e não puramente representativa. A partir dessa tese, a liberdade seria a independência (ou o governo) da razão, porque a razão é a única vontade não heterônoma. 
vontade por oposição ao determinismo das regras do entendimento - a independência dessas duas faculdades é estranha ao texto platônico. Em segundo lugar, porque o conhecimento do bem não impede a nossa espontaneidade, uma vez que, como Kant já nos mostrou ${ }^{23}$, a liberdade como espontaneidade pode ser compatível com o determinismo. ${ }^{24}$

\section{LIBERDADE DE INDIFERENÇA}

Passemos agora à análise que Sócrates faz do indivíduo democrata. Como mencionado na introdução, ela se divide em uma análise genética (558c10-d7, retomada em 559d1-561a5), que define o bem prevalente, e uma normativa (561a6-562a3), que analisa como a deliberação acontece em um caráter determinado por esse bem. A análise genética diz que um indivíduo torna-se democrata ao fim de um conflito interno entre os valores assimilados, por um lado, de uma educação doméstica de um pai sovina e oligarca e, por outro, do convívio social com zangões. O pai oligarca tem como função marcar que esse caráter se origina de uma educação que lhe imputou governo violento sobre os desejos (558d4-5), incapaz de fomentar o aprendizado, as belas ocupações e os discursos verdadeiros que fortalecem o pensamento (560b7-9). Ao conviver com certo tipo de pessoas, os zangões ${ }^{25}$, definidos por vivenciarem os mais variados prazeres a serem experimentados das mais variadas formas (559d7-8), esse indivíduo verá no modo como eles

23 Kant, Crítica da razão prática, § 5.

24 Que um tipo de compatibilismo seja o caso platônico parece ficar claro na reformulação do princípio prático em 436e8-437a1, em que o texto difere por um pequeno e relevante detalhe: em adição ao estabelecido na sua primeira formulação, a segunda versão do princípio do conflito indica que a tese sobre a unidade do agente corresponde à unidade do ser do agente. Robinson (1971: 39) sustenta que a introdução do verbo ser nessa paráfrase resulta em uma consequência indesejável a Platão. Entendo exatamente o oposto, a introdução do verbo ser apresenta o propósito do argumento: relacionar a deliberação com o caráter do agente. A remissão aos contrários indica que "ser" aqui tem sentido predicativo, e que o mesmo agente não será X e não X, i.e., ao não querer fazer opostos, o agente não quer se qualificar por esses opostos como o seu agente. Esse ponto fica mais claro no uso vocabular de "governo de si" como sinônimo de "caráter" em passagens como 579c4-5; 580c2-3; 591e1 e $592 \mathrm{~b} 2$.

25 Para a tradicional associação do zangão a indivíduos que não trabalham (aergoi), cf. Hesíodo, Trabalhos e dias, 302-306. 
realizam os seus desejos razão para também fazê-lo. O resultado é um fortalecimento dos seus desejos reprimidos (559e4-5), gerando um conflito interno entre valores de controle - a reverência, a temperança, o comedimento - e de excesso - a falta de governo, a arrogância e a virilidade (560d9561a4). Essa guerra interna só se apazigua quando passa a prevalecer um bem descrito como a indiferença entre prazeres coercivos e não coercivos

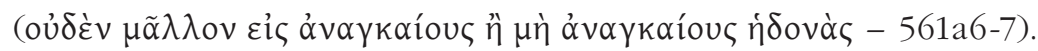

Provavelmente porque esse bem prevalente se define em referência a dois tipos de prazer, a análise da democracia contará, à diferença dos demais regimes, com uma digressão dedicada a essa distinção (558d8559c12). Desejos coercivos são aqueles instrumentalmente ligados ao alcance de bom fins, são condições que precisam ser satisfeitas para atingirmos o que nos é benéfico (558d11-e2). Isso pode ser entendido de duas maneiras: seja como a condição de sobrevivência para que possamos atingir outros fins, como os desejos de nutrição (559a11-b7), seja como parte de uma conexão causal de ações que nos conectam a fins que nos são benéficos, como nas concessões ao prazer feitas pelo oligarca para acumular mais dinheiro (559c3-4). Por oposição, os desejos não coercivos não se ligam causalmente ao benefício (559b8-c1), e isso também pode ser entendido segundo duas categorias: os que são meramente dispensáveis, ou mais especificamente os que são dispensados ao longo de uma boa educação (559b9-10), e aqueles cuja satisfação tem consequências prejudiciais ao nosso corpo ou à nossa alma (559b10-c1).

É relevante à distinção que em nenhum momento foi preciso definir o que propriamente se considera benéfico, i.e., a coerção liga-se a um bem prevalente qualquer, para o que basta a evidência do exemplo do oligarca. Essa indeterminação do bem prevalente é muito relevante para a descrição do democrata como aquele que é indiferente frente a prazeres coercivos e não coercivos. Não há um valor central a dirigir as escolhas do democrata, tal como o dinheiro rege o oligarca e a honra rege o timocrata. Isso significa que nada lhe impede de agir também por qualquer tipo de desejo, desde que ele não seja descrito como vinculado a um bem (561b8-c4). A distinção entre o democrata e o oligarca, portanto, não é uma distinção entre tipos 
de fins, e isso é o que de mais importante a abordagem genética nos diz sobre o democrata: seu bem prevalente é a negação de um bem prevalente. ${ }^{26}$

A segunda parte do argumento, como vimos, trata das consequências da prevalência desse bem para as escolhas e a harmonia das motivações desse indivíduo. Ao negar que a sua escolha esteja causalmente ligada ao bem, o democrata não aceita qualquer classificação ou hierarquia entre desejos, contando-os todos como iguais (561b3-4). ${ }^{27}$ Ele se depara, a cada deliberação, com alternativas que ele considera equipolentes, para as quais não há uma justificativa mais verdadeira do que a outra (561b8-9), ou algo que torne uma delas melhor do que a outra. Essa equipolência caracteriza o democrata precisamente por resistir à estabilização do seu caráter, afinal essa estabilidade proporcionada por um bem prevalente é, a seus olhos, uma forma de coerção.

Essa deliberação que não é previamente determinada sob nenhum aspecto, quero defender aqui, corresponde ao que a tradição chamou de liberdade por indiferença. Essa liberdade, claro, supõe a espontaneidade, já garantida pelo argumento do conflito interno, no entanto, ela tem um requisito suplementar, que se expressa, na formulação cartesiana, do seguinte modo: “... para afirmar ou negar, perseguir ou fugir às coisas que o entendimento nos propõe, agimos de tal maneira que não sentimos absolutamente que alguma força exterior nos obrigue a tanto”.28 A liberdade de indiferença é o principal critério para os escolásticos e os modernos se defenderem contra o determinismo e o compatibilismo, por ser, segundo eles, a única expressão da liberdade positiva. A noção de espontaneidade é negativa: somos livres por não sermos coagidos. Assim, ela ainda é compatível com o determinismo, uma vez que nos coloca em uma série causal de eventos ao escolhermos. Já a liberdade de indiferença seria a única formulação da liberdade absoluta,

26 Com isso concordo com a tese geral de Scott (2000: 23-26) de que, por buscar apenas o que traz deleite sem considerar o valor, os desejos do democrata não são da espécie apetitiva, mas, ao contrário, têm a forma do apetite, de um prazer momentâneo.

27 Parece-me fora de propósito a objeção sobre prazeres maus levantada por Santas (2001: 66), assim como a primazia da satisfação de prazeres no indivíduo democrata. Como o próprio Santas reconhece (Santas 2001: 62), não é o prazer de tipo apetitivo que constitui o valor central da democracia.

28 Descartes, Meditações Metafísicas, IV, § 9. 
capaz, por exemplo, de fundamentar uma teoria libertária, por nos colocar como imune à série causal dos eventos.

Permitam-me uma pequena digressão sobre a história desse conceito que pode por fim remeter a essa passagem da República. Fiz referência a Descartes, mas a mais célebre das versões da liberdade como indiferença é medieval: o asno de Buridan (que jamais constou nos escritos do próprio Buridan), que não tem razões para escolher entre dois montes iguais de feno e morreria de fome. A imagem é uma paródia medieval contra a tese da autonomia da vontade de Buridan, que previa que a vontade é capaz de indicar a inação como resposta a duas alternativas em que não se pudesse distinguir qual é a melhor alternativa. A figura do asno é importante porque Buridan entende que no caso da indiferença humana seria o intelecto a interferir para descobrir qual seria a melhor alternativa. Assim o asno, desprovido de intelecto, seria incapaz de decidir entre os dois montes de feno.

Não constando o exemplo do asno propriamente em Buridan, o seu argumento sobre a inação da vontade parece se reportar a uma expressão antiga do problema, o argumento que aparece, não isento de crítica, no $D e$ Caelo de Aristóteles (295b10-296a23). Trata-se aí da crítica aristotélica ao modelo cosmológico de Anaximandro, que supunha que a Terra estivesse no centro do universo em repouso porque lhe sustentaria um sistema equilibrado de forças tal que nenhuma força sobrepujaria as demais de modo a lhe impor movimento. Aristóteles entende que o argumento é refinado, porém não é verdadeiro. Ele diz que é falso que tudo que esteja no centro só por isso permaneça inerte. Ele alega que a evidência é de que não apenas a Terra esteja no centro, mas que ela se move naturalmente para o centro, sendo o fim do movimento natural de algo o local em que esse algo permanece. Isso seria a seus olhos suficiente para negar que a Terra está no centro por causa da indiferença causada pelo sistema de forças, uma vez que ela estaria no centro devido ao seu movimento natural. Em sua refutação final ele diz:

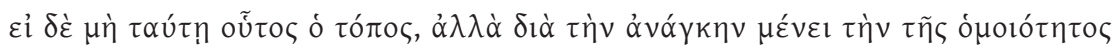

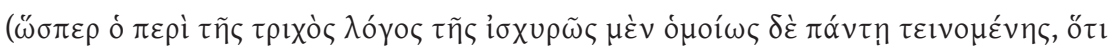




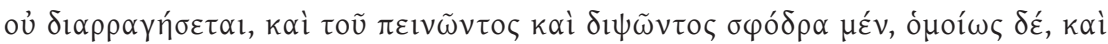

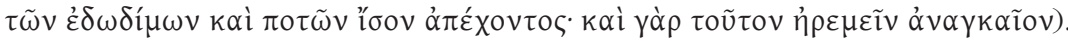

Mas seja então o caso de que este não é o seu local, e que ela repousa devido à coerção da indiferença (tal qual se diz do fio do cabelo que não se romperá por maior que seja a tensão que lhe for aplicada, se ela for uniforme ao longo de todo ele; ou ainda do homem extremamente faminto e sedento, mas ambos igualmente, e a uma igual distância da comida e da bebida, será coagido a permanecer onde está). (Aristóteles, De Caelo, 295b29-34)

Aristóteles usa um exemplo muito parecido com o de Buridan para fazer a mesma redução ao absurdo. Para ambos, alguém que seja governado pela liberdade de indiferença é dominado pela inércia, e incapaz de agir. Se para Buridan essa hipótese é absurda porque o intelecto interviria, para Aristóteles ela é impossível porque a inércia deve ser entendida como um tipo de movimento circular ao redor de si mesmo. O mesmo problema aparece no tratamento que a República dá ao democrata de Platão. Ao longo da análise genética, durante o conflito entre os tipos de desejo, o democrata é comparado aos Lotófagos (560c6-7), aqueles que, segundo Homero, ao comerem o lótus permanecem onde estão e se olvidam do regresso ( $\lambda \omega \tau$ tòv

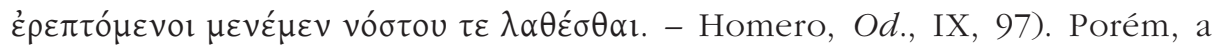
liberdade de indiferença torna-se seu bem prevalente à medida que uma certa regra lhe permite ainda manter a igualdade entre as alternativas. Essa regra é a de dar o governo a cada vez a um desejo que lhe sobrevier, por sorteio (561b3-6): um dia faz ginástica, outro não, noutro faz política, em outro filosofa, e assim vai sem que nenhuma atividade se torne regra de conduta (561c6-d8). É um artifício que o mantém ativo na indiferença e que finalmente permite que a democracia seja um caráter: há um padrão contínuo de escolha que é periodicamente escolher e sempre escolher segundo o acaso. ${ }^{29}$

29 Entendo que o caráter democrata, por essa razão, é um contra-exemplo à interpretação de Graveliedes (2010: 210) de que os caracteres viciosos têm estabilidade porque sua unidade 
Concluindo, o caráter democrático na República é tratado como um agente livre por espontaneidade, portanto imputável por suas escolhas, e também livre por indiferença, portanto não determinado por seus objetos de desejo nem por qualquer sucessão de eventos. O democrata platônico não é um libertino, ele é um libertário.

\section{A Cidade Democrática: A Autoridade individual}

Passemos agora à análise da democracia como regime político. Em sua primeira parte, genética, a análise descreve o bem prevalente em seu contraste com a oligarquia e, quando da sua derrocada, também com a tirania. A oligarquia define-se como um regime corrompido cujo bem central é a riqueza individual ( $550 \mathrm{~d} 7-8$ ), cuja propriedade de organização do todo é de que nenhuma outra capacidade qualifica o governante a não ser a do acúmulo de propriedade privada, ou seja, o critério de distinção entre governantes e governados é simplesmente censitário (550c8-10). A gênese da democracia se explica porque o acúmulo sistêmico das riqueza na oligarquia (555b9-11) dá origem à pobreza extrema (555c1-5) como um corolário do bem prevalente. A democracia é o governo dos pobres (557a25).30 Pobreza aqui tem um sentido muito específico dado por dois critérios: (1) não ter bens privados e (2) não ter sua sobrevivência garantida pela sua cidade. O único recurso que garante a sobrevivência dos pobres é a sua capacidade individual, seja corpórea ou anímica, e isso é o mais importante na explicação do que é uma democracia. A importância maior do segundo sentido de pobreza se evidencia na narrativa da derrocada da democracia,

é mantida pela força. Parece-me muito mais próxima ao texto a interpretação de Hitz (2010: 113) de que é uma certa atuação da razão que estabiliza esses caracteres. Scott (2000: 28) chega a considerar a hipótese de que a alternância é uma atuação racional do democrata, mas a descarta porque supõe que o democrata não poderia fazer uma "escolha racional" (Scott 2000: 29). Creio que, como Scott mesmo reconhece mas finalmente rejeita, a função instrumental da razão no ato das escolhas deve ser reconhecida em todos os casos de caracteres corrompidos (Scott 2000: 34), mais uma vez concordando com Hitz.

30 A passagem 557a2-5, por sinal, comprova que a democracia não pode ser uma modificação na oligarquia, ela supõe que os oligoi, que tinham alguma parte na narrativa, sejam mortos ou exilados. A democracia portanto tem um princípio próprio, independente. 
justificada pelo excesso do seu bem prevalente, que é finalmente descrito como a liberdade (eleutheria - 562b7-c2). Como vimos na seção anterior, a noção de liberdade é equívoca. De um lado, temos uma noção de espontaneidade que é central à caracterização da alma na República, por outro, ela pode ganhar um sentido positivo como negação de toda e qualquer coerção. O ponto chave, a meu ver, é que apenas o segundo desses sentidos pode ser aplicado a um regime político. Ademais, ele é o único que admite graus, e poderia justificar a tese de que há um excesso desse bem.

A especificação do conceito de liberdade fica mais clara na narrativa da derrocada da democracia. O mal que aflige o democrata é, diz Sócrates, o mesmo de que padecia a oligarquia: a presença dos zangões. Como vimos, esses são indivíduos que não distinguem os prazeres coercivos dos não coercivos em suas deliberações; também como vimos, o mal da oligarquia era a presença dos pobres, o que nos leva a identificar a extensão dessa classe de cidadãos. A distinção, no entanto, entre esse mal nos dois regimes é que, na democracia, ele é agravado pela presença da autoridade individual (exousia - 563e8). Exousia é um termo empregado em sentido bem estrito desde o segundo livro da República, com o desafio de Gláucon. Introduzindo sua hipótese de que a justiça só é praticada a contragosto e por incapacidade, ele diz: "Demos a cada um a autoridade (exousia) de fazer o que quiser, ao justo e ao injusto, e acompanhando-os observemos aonde o desejo de cada um deles conduz" (359c1-3). A noção de exousia aqui conjuga dois sentidos: de um lado ela indica a liberdade de indiferença de que tratamos, a falta de restrição ou coação ao querer. Porém, de outro lado, ela não se restringe a uma condição interna, supondo também a condição externa de que a ação deliberada por indiferença se efetive. Não apenas a deliberação, mas também a ação do indivíduo deve ser isenta de coerção, por isso a ideia de autoridade individual. O bem prevalente na democracia não é a eleutheria em sentido geral, mas o seu excesso gerado pela presença da exousia. Ao que diz Sócrates, onde há autoridade individual, cada um pode organizar a sua própria vida do modo que lhe aprouver (557b8-10), sem que ninguém seja constrangido a aceitar as regras de um regime, o nomos 
(563d6-e1). A democracia é um regime onde cada um é "senhor de si"31, e quando se estabelece que "a cidade está embriagada de cidadania e de parrésia, afinal há nela a autoridade individual para se fazer o que se quiser"

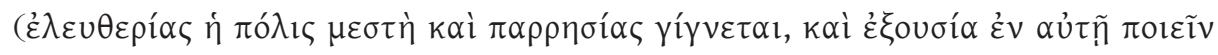

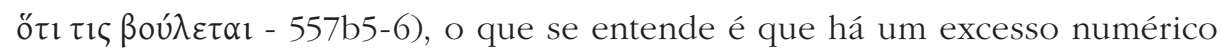
daqueles que são dotados de poder de deliberação política com força executiva e palavra de autoridade, além de que não reconhecem a legitimidade de qualquer tipo de regra comum exterior à sua decisão. ${ }^{32}$

Vemos assim que o peculiar da democracia descrita na República é que a igualdade postulada por ela não é a da distribuição de direitos e deveres aos cidadãos, como talvez esperasse o leitor em busca de uma análise da democracia histórica. Na descrição da regra desse governo, temos que "eles distribuem igualmente a constituição e o governo, e como regra geral os

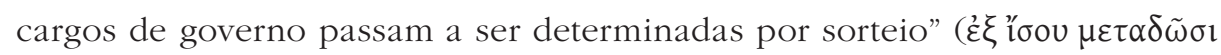

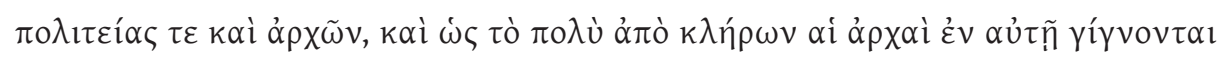
- 557a1-5). Na democracia a que somos apresentados aqui, cada habitante escolhe a sua própria constituição e é governante de si mesmo. Todos os habitantes da cidade são cidadãos porque, ao negar o nomos, consideram que, do simples fato de serem agentes de deliberação e terem liberdade

31 Nesse sentido creio que há no uso do termo eleutheros, usado claramente em oposição ao escravo em 564a3-4, a conotação que lhe é atribuída por sua etimologia, que, segundo Benveniste, remete à raiz "leudh-, "crescer, desenvolver". Ele conclui que "o sentido primeiro não é, como seríamos tentados a imaginar, o de se 'livrar de algo', mas o de pertencer a uma raiz étnica designada por uma metáfora de crescimento vegetal. Esse pertencimento confere um privilégio que o estrangeiro e o escravo jamais conhecem". (Benveniste 1969: v. 1,324). A singularidade da democracia na República é que a autoridade individual permite a cada um: (i) escolher o seu próprio grupo; (2) não reconhecer qualquer imposição externa, o que resulta na paradoxal figura que no jargão popular brasileiro se diria "cacique de nenhum índio".

32 Eleutheria e parresia são paralelas na caracterização da cidade, ambas qualificações de sua embriaguez, tendo a exousía uma posição diferenciada, pela introdução de um kaì que me parece ser expletivo. Seguindo a interpretação que propus, exousia explica a "embriaguez" que indica excesso de cunho negativo dessas propriedades. Veja-se que temos aqui dois traços claramente reconhecíveis da democracia ateniense eleutheria e parresia, que significam respectivamente a regra da participação política e a garantia de expressão das opiniões de todos esses cidadãos. Porém, a sua submissão ao bem primário da exousia deturpa-as, em uma suposta garantia de que essas deliberações e opiniões não encontrarão impedimento externo para a sua efetivação. Ser cidadão de si mesmo gera a recusa a qualquer dever e assim descreve a participação política na democracia como a permissão para todo e qualquer discurso, para toda e qualquer ação. 
por espontaneidade, lhes é dada não só a liberdade por indiferença, a ausência de coerção, mas também a autoridade de sua ação, a exousía. A confusão entre esses conceitos parece tão ampla que Sócrates faz questão de incluir entre os agentes de deliberação política os animais (562e3, 563c3d1), as crianças (562e6-563a1), os escravos (563b5-8) e as mulheres (563c8-10). Em suma, a democracia do livro VIII é a reunião de indivíduos em que modos de vida individuais tornam-se políticos, assemelhando-se muito ao que entendemos por pluralismo. O quadro vivo desse é regime é a famosa passagem do mercado de constituições:

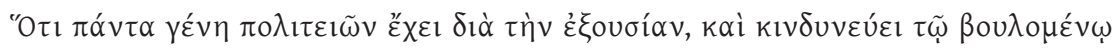

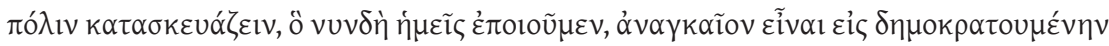

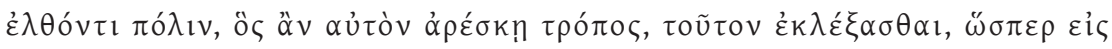

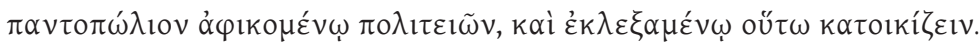

Porque, devido à autoridade individual, há aí todas as espécies de constituições, e pode acontecer que quem quiser organizar uma cidade, como nós agora fazemos, ver-se-á forçado a dirigir-se a uma cidade democrática e escolher o hábito que lhe aprouver, como se chegasse a um mercado de constituições, escolhesse uma e dela fundasse uma colônia. (557d2-7)

Essa passagem foi muito debatida em paralelo com heauton katoikizein de 592b1-4, indicando uma estreita relação entre filosofia e democracia. Não é nosso propósito aqui desenvolver esse tema. Antes nos importa que o pluralismo parece supor que nenhuma razão há para a vida em comum que não aquela de que compartilhar o espaço desse tal mercado. ${ }^{33}$ Contra a leitura de Arendt, citada na introdução desse trabalho, a República reage fortemente contra a dissolução da esfera pública, surpreendentemente identificada com a democracia. É de fato notável que a reação a princípios coercivos externos resulte aqui na ausência de qualquer razão para ações em comum: nada obriga alguém a ir à guerra se a cidade a declarar, ou a manter a paz, ou a exercer o governo, ou a não exercê-lo, se houver uma

33 Cf. Schofield 2016: 113 
condenação contra esse exercício; aliás nenhum decreto jurídico é eficaz porque nenhuma coerção é legítima, ficando criminosos à solta (558a4-7). Aos brasileiros pode parecer o Brasil, a muitos pareceu ser um retrato amargo da Atenas de Platão, mas não é isso o que está em questão: o que estamos vendo é uma análise sobre as consequências do princípio de autoridade individual, de uma proposta política libertária. ${ }^{34}$ A princípio alguém poderia objetar que isso não pode ser um regime político, uma politeia. Claro, esse é um regime corrompido, cuja particularidade é o esgarçamento social, razão pela qual a democracia é chamada de desgoverno (anarkbos - 558c2-3). Ainda que a democracia platônica não possa corresponder ao regime político que hoje chamamos de democracia, parece que a passagem da República faz uma contribuição relevante a um problema que ainda consideramos intrínseco à democracia, a saber, a substituição do compartilhamento de valores típico de uma comunidade ${ }^{35}$ por uma trama social meramente sustentada pela tolerância.

Tolerância é uma proposta de tradução para sungnome em 558a10, termo que a rigor significaria "capacidade de perdão". ${ }^{36}$ Mas a passagem contrapõe dois sentidos de tolerância. O primeiro deles é ligado a questões menores, smikrologia (558a10) ${ }^{37}$, ou seja, a um uso prudencial do perdão em casos isolados. Esse não é o caso da regra de vida democrática, a que se aplica o segundo sentido, ligado a um desprezo proposital a critérios de virtude (559b1). A virtude defendida ao longo do texto da República é um exercício ao longo de toda a vida, e a submissão a esse propósito é incompatível com o princípio da autoridade individual tal como o vimos. Esse segundo sentido de sungnome justifica a tradução por tolerância como princípio de convivência, entendendo por essa palavra a indulgência, o consentimento

\footnotetext{
34 Embora possa concordar com Muller (1997: 75) em que a crítica em relação ao estado democrático não é à eleuthería, discordo que o seu alvo seja o fato de que a democracia não respeita a competência. Mais recentemente Sorensen (2016: 22-34) apresentou boas evidências de que a República reconhece que a democracia ateniense se apoiou na atribuição de cargos políticos segundo competência técnica.

35 Que a República defende a forte comunidade de valores entre os cidadãos atesta, por exemplo, 462a9-b7.

36 Cf. Aristóteles, Ética a Nicômaco, 1143a22-23.

37 Para o sentido de smikrologia, cf. 486a4-6.
} 
tácito, que suporta valores alheios devido à negação da coerção, mas nunca ao seu reconhecimento enquanto tal. ${ }^{38}$ Essa seria a única regra de conduta política, uma regra mínima, em um grupo constituído de "cidadãos de si mesmos" que partilham apenas o espaço do mercado. Uma vez que o grupo se constitui por negar ao governo o poder de sanção ou legislação sobre os indivíduos, ele torna o governo irrelevante, e a função de governar, que ao ver de Sócrates deveria ser entendida como uma honra (558b5), é concedida a qualquer um. Enfim a tolerância é a propriedade que deriva do bem prevalente da democracia e que se prova incapaz de promover qualquer ação comum, que dirá o bem comum. Fica claro porque o bem comum proporcionado por esse regime é transitório e frágil: todas as ações são toleradas e não há força atribuída ao governo.

\section{CONCLUSÃO}

Na sequência do atentado de 11 de setembro de 2001, em entrevista, Jürgen Habermas e Jacques Derrida criticaram o tradicional conceito de tolerância propondo novas definições ${ }^{39}$, ao mesmo tempo que deixaram claras suas divergências sobre a questão. Enquanto Derrida defendia uma completa aceitação do outro pela hospitalidade ${ }^{40}$, Habermas defendia a natureza universal do fundamento moral e legal da ordem liberal. ${ }^{41}$ Ao tratar do tema, Thomas Scanlon ecoa algo do argumento platônico ao definir que uma sociedade tolerante é aquela que é democrática em sua política informal, como uma questão de atitude ${ }^{42}$, porém acrescenta a ressalva de que essa tolerância expressa o reconhecimento de um pertencimento comum, o reconhecimento do direito dos outros a contribuir para a definição de nossa sociedade. ${ }^{43}$ Charles Taylor, que vê a sociedade moderna como uma forma

38 Cf. Schofield 2006: 111, 118-119.

39 Cf. Borradori 2003:41 para Habermas e 127 para Derrida.

40 Borradori 2003: 128-129.

41 Borradori 2003: 42

42 Scanlon 2003: 190.

43 Scanlon 2003: 193. 
de pluralismo em que formas de crença e descrença fragilizam uma à outra ${ }^{44}$, também criticou o que ele chama de relativismo tênue dessa ordem moral por considerar "a intolerância como o pecado intolerável". ${ }^{45}$ Enfim, é bem possível argumentar que a democracia seja um conceito homônimo quando comparamos os antigos gregos a nós, mas, como tentei mostrar, também é possível ver que a ideia de liberdade como um bem prevalente é um problema que atravessa os tempos.

Esse trabalho pretendeu mostrar como a República aborda a democracia segundo dois problemas filosóficos tradicionais. No que tange à psicologia moral, a análise se dedica à liberdade de indiferença e às dificuldades que a eleição desta como um valor se propõe a uma determinada concepção de felicidade. No que tange à filosofia política, a análise se dedica ao problema do pluralismo e das dificuldades que ele propõe à constituição da comunidade.

\section{Bibliografia}

Adam, J. (1902), The Republic of Plato. Cambridge.

Annas, J. (2009), An Introduction to Plato's Republic. Oxford.

Arendt, H. (1958), The Human Condition. Chicago.

Barker, E. (1959), The Political Thought of Plato and Aristotle. New York.

Benveniste, E. (1969), Vocabulaire des instituition indo-europeenes. Paris.

Bertelli, L. (2005), "Platone contro la democrazia (et l'oligarchia)", in M. Vegetti (ed.), Platone: La Repubblica. Napoli, 295-396.

Blössner, N. (1997), Dialogform und Argument: Studien zu Platons Politeia. Stuttgart.

Blössner, N. (2007), "The City-Soul Analogy", in G. R. F. Ferrari (ed.), The Cambridge Companion to Plato's Republic. Cambridge, 345-385.

Bobonich, C. (2002), Plato's Utopia Recast. Oxford.

Borradori, G. (2003), Philosophy in a Time of Terror. Chicago.

Demos, R. (1957), "Paradoxes in Plato's Doctrine of the Ideal State", CQ 7: 164-174.

Ferrari, G. R. F. (2005), City and Soul in Plato's Republic. Chicago.

Frede, D. (2011), "Die ungerechten Verfassungen und die ihnen entsprechenden Menschen (Buch VIII 543a-IX 576b)", in O. Höffe (ed.), Politeia. Berlin,193-208.

Gavrielides, E. (2010), "What Is Wrong with Degenerate Souls in the Republic?", Phronesis 55: 203227.

44 Taylor 2007: 544.

45 Taylor 2007: 484. 


\section{A REPÚBLICA DE PLATÃo SOBRE A DEMOCRACIA}

Hellwig, D. (1980), Adikia in Platons Politeia: Interpretationen zu den Büchern VIII und IX. Amsterdam.

Helmer, E. (2005). "Histoire, politique et pratique aux livres 8 et 9 de la République", in M. Dixsaut \& A. Larivée (eds.), Études sur la République de Platon, Vol. I. De la justice. Éducation, psychologie et politique. Paris, 149-168.

Hitz, Z. (2010), Degenerated Regimes in Plato's Republic, in M. McPherran (ed.) Plato's Republic: $a$ Critical Guide. Cambridge, 103-131.

Muller, R. (1997), La doctrine platonicienne de la liberté. Paris.

Popper, K. (1971), The Open Society and its Enemies: the Spell of Plato. Princeton.

Robinson, R. (1971), "Plato's Separation of Reason from Desire", Phronesis 16: 38-48.

Romilly, J. (1959), "Le classement des constitutions d'Herodote à Aristote", REG 72: 81-99.

Santas, G. (2001), "Plato's Criticism of the "Democratic Man" in the Republic", The Journal of Ethics 5: $57-71$.

Scanlon, T. (2003), The Difficulty of Tolerance: Essays on Political Philosophy. Cambridge.

Schofield, M. (2006), Plato Political Philosophy. Oxford.

Scott, D. (2000), "Plato's Critique of the Democratic Character", Phronesis 45: 19-37.

Slings, S. R. (2002), Platonis Rempublicam. Oxford.

Sorensen, A. D. (2016), Plato on Democracy and Political techne. Leiden.

Stalley, R. F. (1975), "Plato's Argument for the Division of the Reasoning and Appetitive Elements within the Soul", Phronesis 20: 110-128.

Taylor, C. (2007), A Secular Age. Cambridge.

Williams, B. (2008), "The Analogy of City and Soul in Plato's Republic", in G. Fine (ed.), Plato 2 : Ethics, Politics, Religion and the Soul. Oxford, 255-264. 